\title{
Development and Implementation of E-Business Strategies Managed and Applied by Kuwait Airways
}

\author{
Ahmad Al-Fadly ${ }^{1}$ \\ ${ }^{1}$ Faculty of Business Studies, Arab Open University (AOU), Kuwait \\ Correspondence: Ahmad Al-Fadly, Faculty of Business Studies, Arab Open University, Kuwait. E-mail: \\ aalfadly@aou.edu.kw
}

Received: July 1, 2016

Accepted: July 12, 2016

Online Published: August 25, 2016

doi:10.5539/ijef.v8n9p41

URL: http://dx.doi.org/10.5539/ijef.v8n9p41

\begin{abstract}
The chief objective of the current research is to offer significant novel perspectives into the creation and execution of e-business strategies managed and applied by Kuwait Airways, together with an evaluation of their suitability and ability to lead other airlines to secure a competitive advantage. The degree of achievement resulting from the application of e-business strategies for Kuwait Airways depends on the overall value added to its business operations and processes. The researcher adopted a case study of Kuwait Airways (KAC) and Jazeera Airways as a research method. This study shows that a good website can provide positive input for the fundamentals of a trade procedure and change compared to other related technologies, including the telephone, while the basis of the determined benefit is modified, with information becoming an essential asset and electronic commerce being a crucial enabler. This study reveals that the expansion of information through a web-site is related to both technology and policy. The Internet can be considered as a mode or a distribution channel to interact with clients; it is a crucial method to seeking new clients and maintaining associations with existing clients. Both the trade and the clients cannot afford to overlook the latest technology evolution. The current study showed that combining crucial functions including web technologies, marketing, and system solutions can help the KAC to attain competitive benefits.
\end{abstract}

Keywords: Kuwait Airways, e-business, online ticketing, strategies

\section{Introduction}

Seldom would any reader find any mention of the use of the Internet in a business context during the past decade. However, today, businesses are starting to strongly consider the Internet as a main business tool and how to make the best use of it. The Internet, here, plays a role on different levels, and could be considered multi-purpose. It has become more than simply a tool for communicating with others electronically, moving to the level of highly interactive programs designed to sell products and services (Imhoff et al., 2001).

The purpose of this study is to offer significant set up of e-business strategies managed and applied by Kuwait Airways, together with an evaluation of their suitability and ability to lead other airlines to secure a competitive advantage. The study also adopted a case study of Jazeera Airways to analyze both airlines' e-business strategies and its associated achievement in their business.

The degree of achievement reached through utilization of e-business strategy for Kuwait Airways relies on the general value added to the business operations and processes. At present, many airlines are turning their attention to e-business to safeguard their resources and to protect their customers' loyalty in the short- and long-terms, in addition to the traditional objectives of being successful in today's direly competitive environment.

\section{Case Study of Kuwait Airways}

Kuwait Airways is the national airline of Kuwait. Kuwait Airways is a state-owned enterprise, which might be heading towards privatization. Amid increased local competition, the customer base has witnessed a great rift with the advent of local economical airlines, such as Al-Jazeera, among other international airlines coming mainly from neighboring GCC countries.

According to Binggeli et al. (2002), throughout its history, KAC has suffered severe losses. It lost a significant number of planes during the Iraqi occupation of Kuwait in 1990. The company was indebted with a total of KWD 381.99 million (about USD \$1.4 billion) to finance its recovery. In 2006, the Kuwaiti airline management 
initiated a plan to renew and expand its fleet base by leasing 19 airplanes worth KWD 818.4 million (USD \$3 billion). In terms of its future plans, an initial public offering (IPO) of $40 \%$ of its shares is an option still under great consideration by top management at the Kuwaiti airline operator, delayed only by the global economic crisis.

Among the many goals of the KAC is to distinguish itself from its competitors in the market, especially when considering the current dire competition, through building a competitive foothold for itself. As a step towards this goal, KAC decided to launch its own web portal, which offers a fairly wide range of services: baggage tracking, shipment tracking, flight schedules, follow-up on holiday offers and promotions provided by KAC to travelers, and access to Oasis Club information (www.kuwaitairways.com).

KAC launched a new web site (www.kuwait-airways.com) to serve as a business portal facilitating access to its services and travel packages. One of the goals set by the Kuwaiti airline through this step is to re-establish a network that is capable of attracting passengers from more than 46 countries.

The Kuwait airline business is, in itself, a highly challenging operation. Several, sometimes parallel, tasks must all be running in the most perfect manner. Passenger data, rates, and aviation schedules should be maintained accurately, and due to the rapidly increasing and fluctuating market, sales promotions and marketing activities all change in a very rapid manner, since, for example, reservations and whole flights can get cancelled or delayed. Airline operators work in a multi-cultural setting, with different locations and destinations worldwide, thus maximizing the pressure experienced by its crew and staff. Failure to reap some of the fruits provided by the Internet may result in the company's overall loss of opportunities to redress balance with competitors and meet the increasing set of demands from its own clients (TIA, 2008).

Kuwait Airways has marketing department and call center department that handle all sorts of interactions with customers. Online ticket enquiries submitted by travelers and reservations systems, as well as through the corporate website are all in place. In order to reach a larger base locally and internationally, Kuwait Airways must strongly consider the application of technological solutions. A focus on specialized and custom-developed software designed for similar airways companies must be considered for adoption.

This research aims to identify the various needs and requirements of marketing and customer satisfaction by means of implementing specialized web-based software which would eventually help achieve these objectives.

Through its venture to take such a step, several e-commerce principles were pioneered by the airline operator. Among the most important of these principles is being the first B2B information exchange portal. This environment provided an excellent opportunity for operations research (OR) modeling. Due to several challenges posed to airlines for driving their operational costs lower (providing semi-lower fares for passengers), such models continue to be adopted by several airlines worldwide. The Internet has provided an excellent alternative for several airlines worldwide, giving them the opportunity to decrease the ticket fares to some extent (Middle East Airline, 2014).

Whatever business model airlines opt for, to be successful, airlines need to understand how the Web and e-commerce affects their business. Due to the wide and eminent dangers surrounding airlines nowadays (especially high fares), the use of online services might act as an easy way out of such terrible circumstances that endanger their business.

This study will be carried within the Kuwait Airways environment and will review the company's marketing and customer interaction environments. However, marketing will limitedly focus on the business-to-customer (B2C) environment, whereas customer interaction examination will be analyzed through service recovery in which customers are allowed to provide feedback and submit complaints. The data resulting from such information will help Kuwait Airways develop and enhance their business environment.

\subsection{Objectives Can Be Summarized into the Following Points}

- Identify factors that play an important role in the marketing and customer interaction environment within Kuwait Airways.

- Put forth a web-based $24 \times 7$ online software solution to enhance marketing operation and customer interaction.

- Recommend a perfectly suitable solution highlighting its usages and benefits, thereby launching the solution.

- Incorporate this solution with the existing Customer Relationship Management (CRM) system. 


\section{Case Study of Jazeera Airways}

Jazeera Airways is the only privately owned airline in the Middle East. This airline is owned by Kuwaiti nationals and it is the second low-cost airline in the Gulf region after the Sharjah-based Air Arabia, and is designed to attract customers as well as leisure travelers in light of present weak financial conditions by providing a low-cost air fare for travelers. Also there is no main direct competition in Kuwait, as local competition is confined to ailing incumbent, Kuwait Airways. Jazeera Airways adopted a low-cost business strategy, such as the provision of in-flight meals, by reducing cost initiatives including high aircraft utilization, the outsourcing of engineering and servicing, and ticketless travel.

Jazeera Airways had defined many priorities for its future expansion. As part of a 2012 master plan, it aimed to boost yields, specifically meaning the revenue increased by carrying one passenger one kilometer. In addition, Jazeera aimed to increase its load factor from 66 percent in the year of 2012 to 68 percent in 2014. The load factor refers to the proportion of the total available capacity of the airline's fleet that is actually being used. Jazeera's load factor for the third quarter stood at 73.6 percent, with average yield at KD60 (Jazeera Airways, 2016).

Booking flights online through Jazeera's website is a simple process. The ease of use is the main attractive technique of Jazeera's web site. All frequent travelers can look forward to the fact that the airline has a monthly rotating menu and so they have a variety in their meals. Business class travelers can look forward to exclusive check-in lines as well as business class lounge access and special meals on board. In addition, Jazeera airways' baggage allowance is rather generous, allowing every passenger, including those in economy class, to carry 40 $\mathrm{kg}$ of baggage free of cost. Business class travelers are allowed $60 \mathrm{~kg}$ of free baggage allowance (Jazeera Airways, 2016).

Jazeera adopted Cleartrip functionality on their website, which is a single-window site that helps online customers to make all their Jazeera Airways bookings easily. Any bookings made at the last minute can easily be tracked based on the guidelines provided on the site. For travelers of Jazeera Airways, PNR status will be available at the click of a button. The main aim of Cleartrip is to ensure that the booking process is an efficient one (Jazeera Airways, 2016).

From being able to offer to customers a range of information on multiple domestic and international routes across a one single page to being able to track their particular flight, the site has all the information customers will need. Browse through the Jazeera website to learn all about flights, discounts, ground services, and more.

\section{Software}

Businesses are constantly using the Internet to facilitate and speed up communicational process (whether internally or in a B2B environment), on the one hand to better manage their own inventory, and on the other hand to deal with the requirements of providing and supplying such inventory to clients and customers. Other institutions use the Internet as a means of broadcasting their own institutional culture, more internally than internationally. For example, banking institutions currently offer services to their customers via web portals, with other services provided for consumers (like purchasing a car, laptop, or any other service through the bank). Other businesses have captured the power of the Internet to create new alternatives and opportunities following the model of eBay, building a single channel where traders and clients can meet together (Lankes, 2007). Such a trend can be traced, to some extent, to the models of Tradekey.com and alibaba.com. (This model is more specifically called e-business, where companies operate almost entirely through the internet).

The software trade is currently witnessing an increasing boom worldwide with total revenues reaching at least $\$ 600$ billion annually, one third of which comes from products and the rest from software services. Throughout the whole world, there are more than 35,000 software service providers with an average of more than four employees each. The majority of these companies, for example Accenture, Cap Gemini, and Ernst \& Young, drive their revenues mainly from services. Over the last few years, services and maintenance shares in corporate revenues witnessed some kind of increase, within software business and other business sections (Nigel et al., 2001).

Software business encompasses widely different technologies and service sectors. That's why a software strategy should be developed for each model separately and individually. Indeed, different businesses, customers, and market segments require different strategies and capabilities to be adopted based on each model's particular specifications. Culture and client expectations differ in every country and business setting, and failing to meet the expectations of either may result in further loss of potential clients (Strout, 2002). 


\section{Online Travel Market}

Use of the Internet by travelers to plan and book their trips continues to grow rapidly, especially in the Arab region and Kuwait, given the high number of expatriates available. In the United States, according to the Travel Industry Association (TIA, 2008) more than 75 million online travelers used the Internet in 2006 to get information on destinations or to check prices and schedules. From 1999 to 2006, online bookings showed a remarkable double-digit growth for four consecutive years, with a spectacular $58 \%$ growth in 2001, followed by a 25\% growth in 2002. The Association also showed that as growth of the online traveler market slugged, through "the number of online travelers who actually use the Internet to plan trips has remained relatively stable." TIA also added that $67 \%$ of online travelers say they consult the Internet to get information on destinations or to check prices or schedules.

Airline tickets come as the first item to be purchased online and used for online trading between travelers and airlines through the web. More than one-third of online travel bookers pay for or make their reservations online (Nigel et al., 2001), thus the online airline portal can be used to add other services or even gather customers from another, perhaps different operational sector.

\subsection{Airline Expenses and Customer Usage of Airline Websites}

Nowadays, there some imagine that airlines could be the biggest consumers of the e-commerce business pie, whether they gain support from their governments or not. The typical character of an airline and its general framework further strengthen such an assumption. The cost of airlines is comprised of two aspects direct and indirect operation. Direct operation is costs like fuel and salaries, which cover $60 \%$ of the total expenses, and indirect cost, which is the distribution cost and covers $40 \%$. Direct operating outlays are generally fixed and the airline cannot do much to reduce these outlays. Hence, the majority of airlines emphasize their cost-saving endeavors on lowering indirect outlays (Gefen et al., 2003).

According to Yang (2001), and based on such a distinction, the Internet and e-commerce both have the ability to assume a very important role. Distribution costs play a very important role in driving direct costs higher, with elements involved such as (1) Reservation system, (2) Sales offices, (3) Advertising, (4) Agent fees and commissions, and (5) Ticketing fees. According to Yang, air tickets will sell the same seats at difference prices. For early bookings, cheaper fares will be provided by airlines and the fare will go up and down according to time. Because of this, some of the tickets cannot be sold before departure, at which time it becomes "spoiled" (Yang, 2001).

On the other hand, earlier sales of seats can be discounted, which lessens revenues greatly. Some airlines strive for certain rules and conditions to apply to "late-coming" passengers, thus driving away low-fare ticket sales. These factors are illustrated below (Table 1) (Zhang \& Prybutok, 2005).

Table1. Factors affecting pricing

\begin{tabular}{ll}
\hline Length of stay & For instance, if a Saturday-night stay exists or not. \\
\hline Advance purchase & This indicates how early the ticket is bought. Generally, a ticket bought14 days before travel \\
& is needed so as to get a discount ticket. \\
Frequent Flyer Membership & If one uses the same airline regularly, one gets specific advantages, including free tickets. \\
Alliance/Code share deals & The number of airlines entering into alliances has increased wherein they share their \\
& inventory on specific routes to lower or eliminate competition. \\
Point of sale (POS) & The cost of the air ticket varies based on the location it is purchased from. \\
Group price & A discount is generally provided for group bookings. \\
Booking agents' special offers & Specific travel agents are given special offers by the airline so that they can sell the tickets at \\
& a reduced price to the passengers. \\
\hline
\end{tabular}

\subsection{Airline Usage of Technology}

For a better realization of the advantages of e-commerce and to turn away from the dilution previously mentioned, airlines seek assistance from innovative tools to manage such revenue before it is diluted. These tools are called revenue management systems and Internet distribution systems. The revenue management system uses a computer to analyze historical booking trends, comparing them to current bookings to project passenger traffic demand for market segments in the future, and even for destination(s). That is, it analyzes passenger pricing behavior and how much consumers are willing to pay at a certain travel rate. This could facilitate better allocation of seats on flights and determine how to divide seats among different levels. This is one particular 
purpose for which many airlines use such systems (Nigel et al., 2001). However, a revenue management system needs a distribution mechanism to transmit its data. Yang states that, the market's competitive activities should be evaluated all the time so that, airlines can understand the present market situation and take immediate action on activities such as flights, itineraries, prices, and number of seats for display on the web.

This is an easy, dynamic, and versatile way to price seats in a single flight or a group of flights, thus relieving heavy loads for airline management. This occurs in such way that Yang points out that internet booking can increase profits and customer satisfaction for the airline industry (Yang, 2001).

\subsection{Benefits of Using the Internet}

Gefen et al. (2003) states that; the web activities and use of an online ticketing is used by majority of airlines. The online ticketing systems are used by plenty of travelers, and there are no problems seen when we compare this use to other businesses. It seems that this web technology was specially made for the travel industry.

The airline industry uses their websites not only for online ticketing, but also for hotels, and car rentals, which allows a client to participate in attempting to earn new rewards shares in the online category (Gefen et al., 2003).

According to Kalakota et al. (2001), to keep customers loyal, airlines managed to establish customer-friendly front-end systems for already-established information systems. The travel industry was among the earliest to go online. Since travel has few geographical boundaries, and, thanks to the widespread public approval of e-tickets, which airlines aggressively pushed, the airlines did not face the issues and problems of other industries. It seemed that the web technology was specifically made for travel industry.

With existing players and new entrants trying to capture a slice of the online segment of customers, new travel-related websites were springing up or reinventing themselves constantly. Many airlines, hotels, car rental companies, CRSs and national and municipal tourist organizations opted for online solutions.

According to Consumer Reports Web Watch Investigations: Travel: Fare-Jumping, Bias, Lowest Fares, Internet Travel Industry Report, the industry was also leveraged relationships with emerging online service providers to work with business and leisure travelers in a cost-effective manner.

\subsection{Customer Expectation of Websites}

The use of the Internet has increased all over the world very quickly. In addition, customers now expect web based self-services from service providers. Globally, people depend on the internet for their daily life for gathering information, online purchases, etc. The increase of this dependency on the internet is also created by the radical rise of self-service choices present for the Internet users (Lankes, 2007). Thus, enterprise website quality has become a crucial sign of how well a firm can fulfill its clients' needs. Another novel test is the quick rise of the anticipations and the degree of refinement of e-customers.

Murphy et al. (2006) indicates a business-to-business model based on five phases of using the Internet: an email address, basic web site, web site aspects to endorse planning, sales and secure online ordering, and vendor aspects. On the other hand, a business-to-consumer model is based on three stages of providing: information, interactivity, and personalization. In the case of hotels, it could start with the email address and essential room and contact details on their website. This could gradually develop into the addition of interactive website features, such as including options for different languages or brochure requests and email reply strategies. This could then be developed through adding personalization, such as online booking and payment methods and modes. Since every corporate hotel recognizes the importance of the Internet, hotels should add innovation into their website.

\subsection{Website Content}

The contents of a website can be described as quality of the design, use of software, attractiveness of design, graphics, ease of access, data information etc. More than that, it will be depend on how users identify the web service quality and their requirements for websites (Udo et al., 2008). The quality of the content can depend on how much information is on the site, or maybe the attraction of the website home page will identify with the users, and then they will decide the website's content quality.

As per Koernig (2003), valuable web site content can affirmatively impact the client's outlook towards the quality of web-based services they obtain and thus can result in the behavioral intent to continue to employ the website services. Valuable web content can ensure that the web-based service is more "actual" and practical to the e-customer.

\subsection{Proposed Solution and Technology}

The technology, as defined by IT professionals, is built around passing an extensible markup language 
(XML)-formatted SOAP message. It is clearly marked off any other programming language, yet designed to support distributed computing online. Web services are offered through an interface that enables administrators and webmasters to manage and administrate them aptly for institutional or customer usage (Tehrani, 2001).

According to Strassmann (1999), “A typical web service acts as middleware, as it encompasses different platforms together. In this environment, and as the service is platform-independent, users are free to set and define their own personalized tags. Below are some tools that will are useful for a launch and development of a web portal:

- $\quad$ Visual Studio 2008

- $\quad$ Microsoft SQL/MySQL

- Java Web Service Developer Pack (Java WSDP 2.0) and API packages.

The application programming interface (API) relates to accessibility of various people to the web site through travel agents; it's also expected to increase the traffic of the web site by using some referral links to other services on the website.

\subsection{Perceived Risk}

The major risk in e-business is online shopping. There are lots of online shoppers that face security risks as their main reason for online shopping, which may lead to consumers being afraid to deal with online shopping. Nowadays, the latest technologies were adopted by companies to secure their online consumers. Also, campaign and guarantee policies can be provided by companies to secure their consumers. In addition, the perceived risk also includes individual risk, financial risk, financial risk, and psychological risk (Pavlou, 2003).

\subsection{Convenience of Service}

Ease of use is the main advantage of online shopping. Users are very busy with their daily lives and most users are willing to save their time in front of computer. According to Yang (2001), online users prefer convenience for their online purchase. During their purchase, ease of use provides an attractive option for the users, which will attract more shoppers for their product and services.

\subsection{Individual IT Skill Difference}

The skills of IT users are not same; they differ among their experience and education. The online shoppers depend on their ability to choose the right technology to get e-services. The number of online users is increasing day by day (Rodney \& Heide, 1996). Rowley (2006) argues that; the experience and knowledge of a consumer is very important in e-business, a method through which companies can improve their policies, access facilities, and ease of use. In this way, online businesses can support their clients to keep them as satisfied customers.

\section{Customer Relationship Management (CRM)}

Customer Relationship Management (CRM) is not only related with internet technology, but also this is applied as a marketing method which is supported by technology. Sterne (2001) argues that; nowadays, the majority of humans are connected through the Internet all over the world. Social media is used by $90 \%$ of the world, and they are connected together to share their knowledge and information. A study by Sterne (2001) recommends that online companies consider that their consumers feel that they are interacting with humans rather than with machines.

\section{Case Study Analysis and Result}

According to the case study, Kuwait Airways has been mismanaged for years, operating like a government ministry with bottomless financial resources rather than a business designed to turn a profit, leaving the airline drowning in crushing debt. In many ways Jazeera Airways is the polar opposite of Kuwait Airways. Jazeera Airways is a privately owned, nimble, low-cost airline, operating a single type of aircraft. The airline makes deliberate strategic moves to remain profitable. The case study of Jazeera Airways mentioned that; Jazeera Airways' online booking process is simple. All frequent travelers can look forward to the fact that the airline has a monthly rotating menu and so they have a variety in their meals. With Jazeera Airways' online check in facility, the process is easy for passengers. Business class travelers can look forward to exclusive check-in lines and business class lounge access and special meals on board. In addition, Jazeera Airways' baggage allowance is rather generous, allowing every passenger, including those in the economy class, to carry $40 \mathrm{~kg}$ of baggage free of cost. Business class travelers are allowed $60 \mathrm{~kg}$ of free baggage allowance.

Jazeera adopted Cleartrip facilities on their website, which is a single-window site that helps online customers to make all their Jazeera Airways bookings easily. Any bookings made at the last minute can easily be tracked 
based on the guidelines provided on the site. Jazeera Airways' PNR status will be available at the click of a button. The main aim of Cleartrip is to ensure that the booking process is an efficient one.

Literature reviews show that; graphics can turn the most boring site into a professional site, that graphic design is art. Graphic design is communication. Conceivably, to most highly attracted buyers; graphic design is a tool for marketing. The effective use of graphic design creates positive, relevant, and memorable associations with a business. KAC didn't show the importance of photography in the design of their site. But good photography is so important on a website, which can increase the brand trust and quality. We can identify that KAC did not adopt multimedia functions in their website. As we know, the Internet is ready to handle stylish audio and video files. Plus, Internet skills are improving every day. Video elements are a further tool can be employed in a marketing campaign. KAC can provide music that sets the tone for their product or services. Site traffic is increasing, which means increased web traffic and more business to the KAC site, and ultimately the majority of users will be willing to be a customer of KAC, but still they are in need of improvements on their site.

\section{Summary of Findings}

The study found that in order to provide an adequate answer to the research question "Can an airline increase market share and customer loyalty by achieving competitive advantage utilizing e-business models?" one must fully understand the main features of websites and their relevance to airline competitive advantage.

Moreover, the study found that the development of the information economy is as much about strategy as it is about technology. The Internet is not just another medium or a distribution channel to reach customers; it is an important medium to find new customers and continue relationships with current customers.

There is still hesitation within KAC about committing any major effort to IT (website), let alone about fundamentally rethinking their business strategy in line with new opportunities. The reasons for this hesitation include:

- Lack of awareness and understanding of the opportunities, implications, and uncertainty about the appropriate business model for web design;

- Concerns about interoperability and the risk that competition between major suppliers (e.g., Microsoft and Netscape) will lead to incompatible sets of standards;

- Uncertainty about applicable technology and software on the KAC website; and

- Lack of usability of the technology, difficulties in performing slightly more complicated electronic commerce than merely being present with a web page.

\section{Recommendations and Conclusion}

Web services are offered in the form of website plug-ins that is installed in other travel agent web sites. These APIs should be served through the web development department. The aim of this API is to facilitate accessibility for various people to the website through travel agents; also, it's expected to increase the traffic to the website through referral links to other services.

This study shows that a good website can provide positive input to the fundamentals of a trade procedure and change compared to other related technologies, including the telephone, while the basis of determined benefit is modified, with information becoming an essential asset and electronic commerce being a crucial enabler.

This study reveals that the expansion of information through a website is related to both technology and policy. The Internet can be considered a mode or a distribution channel to interact with clients; it is a crucial method to seeking new clients and maintaining associations with the present clients. Both the trades and the clients cannot afford to overlook this novel technology evolution. People using the Internet are no longer those who were considered to be "techie's". They now are people belonging to different age groups from varied areas across the globe. A typical web service acts as middleware, as it encompasses different platforms together. In this environment, and since the service is platform-independent, users are free to set and define their own personalized tags. Below are some tools that can be made use of for the launch and development of a web portal, such as an API, the aim of which is website accessibility through travel agents.

According to Airline Business, (2013), there are various ideas about how the API should function regarding the following:

- The book's new form;

- $\quad$ Flight status;

- Search directions; 
- $\quad$ Flight schedules.

This API should have a version for clients and a version for travel agents' offices, which will ensure the principles of B2B for Kuwait Airways.

\section{References}

Airline Business. (2013). Asian: The year 2013 was to bring big e-commerce development by Asian airlines. While little of substance was delivered, 2001 looks to be a true break-pout year, March, p. 74.

Binggeli, U., Pommes, C., Granville, G., \& Gupta, S. (2002). Flying High with Airline CRM. McKinsey \& Company Whitepaper.

Gefen, D., Karahanna, E., \& Straub, D. W. (2003). Inexperience and experience with online stores: The importance of TAM and trust. IEEE Transactions on Engineering Management, 50(3), 307-321. http://dx.doi.org/10.1109/TEM.2003.817277

Imhoff, C., Loftis, L., \& Geiger, J. (2001). Small Business Development Center. Building the Customer- Centric Enterprise Data Warehousing Techniques for Supporting Customer Relationship Management. New York: Wiley Computer Publishing.

Jazeera Airways. (2016). Retrieved June 20, 2016 from http://jazeeraairways.com/TravelGuide/checkin.aspx?Lang=En

Kalakota, R., Robinson, M., \& Kalakota, R. (2001). E-business 2.0: Roadmap for success. Boston, MA, Addison-Wesley.

Koernig, S. K. (2003). E-scapes: The electronic physical environment and service tangibility. Psychology \& Marketing, 20(2), 151-167. http://dx.doi.org/10.1002/mar.10065

Lankes, D. R. (2007). Credibility on the internet: Shifting from authority to reliability. Journal of Documentation, 64(5), 667-686. http://dx.doi.org/10.1108/00220410810899709

Middle East Airlines. (2014). The Middle East Airlines industry. Applied Technologies Group Whitepaper.

Murphy, J., Schegg, R., \& Olaru, D. (2006). Investigating the evolution of hotel Internet adoption. Information Technology \& Tourism, 8(3), 161-177. http://dx.doi.org/10.3727/109830506778690830

Nigel, F., David, M., \& Nicola, M. (2001). The role of individual differences in internet searching: An empirical study. Journal of American Society for Information Science and Technology, 52(12), 1049-1066. http://dx.doi.org/10.1002/asi.1165

Pavlou, P. A. (2003). Consumer acceptance of electronic commerce-integrating trust and risk with the technology acceptance model. International Journal of Electronic Commerce, 7(3), 69-103.

Rodney, S., \& Heide, J. B. (1996). Controlling supplier opportunism in industrial relationships. Journal of Marketing Research, 33(4), 431-441. http://dx.doi.org/10.2307/3152214

Rowley, J. (2006). An analysis of the e-service literature: Towards a research agenda. Internet Research, 16(3), 339-359. http://dx.doi.org/10.1108/10662240610673736

Sterne, J. (2001). Customer Service on the Internet. Toronto, Canada: Wiley Computer Publishing.

Strassmann, P. A. (1999). Numbers indicate that firms overspend on information management. InfoWorld.

Strout, E. (2002). To tell the truth. Sales and Marketing Management, 154(July), 40-47.

Tehrani, R. (2001). Viagra for the profit-driven soul. Customer Interaction Solutions, 19(8), 12-14.

TIA. (2008). Travelers' use of the Internet. Travel Industry Association of America, Travel Industry Association of America, Washington DC.

Udo, G. J., Bagchi, K. K., \& Kris, P. J. (2008). Assessing web service quality dimensions: The e-servperf approach. Issues in Information Systems, 9(2), 313-322.

Yang, (2001). E-Commerce in airline business. PROS Revenue Management, Paper presented at the International Symposium on Government in E-Commerce Development, Ningbo, China April 23-24, 2001.

Zhang, X., \& Prybutok, V. R. (2005). A consumer perspective of e-service quality. IEEE Transactions on Engineering Management, 15(4), 461-477. http://dx.doi.org/10.1109/TEM.2005.856568 


\section{Copyrights}

Copyright for this article is retained by the author(s), with first publication rights granted to the journal.

This is an open-access article distributed under the terms and conditions of the Creative Commons Attribution license (http://creativecommons.org/licenses/by/4.0/). 